\title{
Implementasi Artificial Bee Colony untuk Pemilihan Titik Pusat pada Algoritma $K$-means
}

\author{
Ario Bagus Nugroho, Diana Purwitasari, dan Chastine Fatichah \\ Jurusan Teknik Informatika, Fakultas Teknologi Informasi, Institut Teknologi Sepuluh Nopember
}

(ITS)

Jl. Arief Rahman Hakim, Surabaya 60111 Indonesia

e-mail:diana@if.its.ac.id, chf@its-sby.edu

\begin{abstract}
Abstrak-Klastering merupakan metode yang digunakan untuk membagi data menjadi beberapa kelompok bagian. K-means (KM) merupakan algoritma yang sering digunakan dalam klastering, hanya saja hasil dari KM sering kali terjebak di lokal optima. Artificial Bee Colony (ABC) merupakan algoritma yang bekerja berdasarkan cara lebah mencari makan, $\mathrm{ABC}$ terkenal mampu lolos dari jebakan lokal optima dengan mengenali mana hasil yang terbaik dari serangkaian hasil optimal. Menggabungkan ABCKM dimulai dengan memilih sumber makanan awal secara acak dan menggunakan KM untuk menyelesaikan semua permasalahan klastering pada setiap langkah ABC berikutnya serta menyimpan sumber makanan terbaik disetiap iterasinya. Sumber-sumber terbaik tersebut akan dipilih sumber makanan terbaiknya berdasarkan probabilitas kecocokannya masing-masing. Hasil dari implementasi algoritma ABCKM ini adalah data yang telah dibagi berdasarkan sumber terbaik. Setelah di evaluasi menggunakan algoritma silhouette dapat dibuktikan bahwa rata-rata nilai koefisien pada 5 buah dataset adalah 0.65 yang berarti data telah di-klaster dengan baik.
\end{abstract}

Kata Kunci-Artificial Bee Colony, K-means, klastering

\section{PENDAHULUAN}

$\mathrm{K}$ LASTERING digunakan untuk membagi data menjadi kelompok yang homogen, banyak aplikasi dari klastering yang telah dirasakan manfaatnya seperti segmentasi citra, mengenali segmentasi pasar dalam bisnis, temu kembali informasi dan juga dalam merangkum data [1].

Salah satu implementasi klastering untuk segmentasi pasar dalam bisnis digunakan untuk membagi kelompok konsumen berdasarkan kebutuhan, perilaku dan karakteristik masingmasing kelompok konsumen agar pelaku bisnis dapat memasarkan produknya dengan lebih efektif.

$K$-means (KM) merupakan salah satu algoritma klasterisasi yang umum digunakan karena kemudahan dan relatif cepatnya waktu yang dibutuhkan dalam menjalankan pembelajaran. Permasalahannya hasil klaster KM kerap mengacu pada solusi lokal optima [3]. Yaitu solusi yang optimal (baik maksimal ataupun minimal) pada kandidat solusi di tetangga terdekatnya saja bukan keseluruhan dari semua solusi yang ada atau yang biasa disebut global optima.

Maka dari itu diusulkan agar mengimplementasikan algoritma Artificial Bee Colony (ABC) yang biasa digunakan untuk pencarian global seperti permasalahan Travelling Salesman Problem (TSP) yang mencari rute termurah dan efisien untuk mencapai tujuan para sales yang sangat banyak. Cara kerja $\mathrm{ABC}$ yang meniru cara lebah mencari makan (foregaging) nektar ini di mulai dengan terbangnya employed bee yang mencari sumber makanan yang kemudian memberikan informasi letaknya kepada onlooker bee dengan cara menari.

Onlooker bee akan membandingkan nilai probabilitas masing-masing letak sumber makanannya dan mencari sumber makanan disekitar sumber yang dipilih, hingga seketika sumber makanan yang ditemukan saat ini lebih banyak dari sumber sebelumnya maka lebah tersebut akan melupakan informasi tentang sumber makanan terbanyak sebelumnya dan untuk sumber makanan yang habis atau tidak berubah sumber makanan tersebut akan ditinggalkan dan dilupakan serta lebah tersebut akan menjadi scout bee yang akan mengintai sebuah sumber makanan baru yang akan diciptakan di ruang pencarian. Langkah-langkah tersebut akan dilakukan hingga ditemukan solusi global optima [2].

Pengaplikasian lain dari $\mathrm{ABC}$ adalah penjadwalan produksi barang, yang akan digunakan untuk menjaga siklus produksi, yaitu serangkaian aktifitas bisnis seperti pencatatan order dari pelanggan, pencatatan bahan mentah, juga pencatatan gaji karyawan, dan kegiatan pengolahan data secara kontinu. Peran ABC pada pengolahan data siklus bisnis akan sangat signifikan dimana akan dibutuhkan perencanaan jumlah produksi dan persediaan, menjadwalkan proses produksi dengan meminimalkan jumlah waktu proses yang dibutuhkan untuk menyelesaikan seluruh proses produksi, dan juga mengoptimalkan biaya pokok produksi.

Metode klastering yang ditawarkan menggabungkan kedua algoritma tersebut menjadi Artificial Bee Colony K-means (ABCKM). Metode ini akan melengkapi cara kerja algoritma KM pada pemilihan centroid dan dengan sifat pencarian global dari $\mathrm{ABC}$, kumpulan sumber makanan yang telah disimpan akan dipilih sehingga didapatkan sumber makanan optimal untuk membagi datanya.

\section{DATA DAN METODE ABCKM}

\section{A. Dataset}

Data masukan yang akan digunakan terdiri dari lima buah dataset yang terdiri dari :

1. Wholesale Customer yang merupakan data penjualan kebutuhan sehari-hari pada suatu distributor Wholesale 
yang memiliki 6 atribut numerikal yaitu penjualan makanan dan kebutuhan rumah tangga seperti fresh, milk, grocery, frozen, detergents and paper, dan delicatessen, di dua kota besar dan satu kota komplementer yang merupakan gabungan kota-kota lain, baik melalui restoran, hotel, cafe maupun toko eceran. Yang di dapatkan dari: https://archive.ics.uci.edu/ml/datasets/Wholesale+custo $\underline{\text { mers }}$

2. Crime Rate America yang merupakan data banyaknya kota dan kejahatannya disetiap populasi 100.000 pada 1970 di Amerika yang memiliki 16 baris nama kota dan 7 atribut numerik yang terdiri dari kejahatan pembunuhan, pemerkosaan, perampokan, pencurian, penyerangan, pencurian mobil, penggarongan. Yang didapatkan dari: http://people.sc.fsu.edu/ jburkardt/datasets/hartigan/file0 3.txt

3. Birth and Death Rates yang merupakan data banyaknya Negara terhadap angka kehidupan dan kematiannya disetiap 1000 orang pada tahun 1966 yang didapatkan dari:

http://people.sc.fsu.edu/ jburkardt/datasets/hartigan/file2 $\underline{\text { 6.txt }}$

4. Iris dataset yang merupakan data yang mencatat ukuran 3 jenis kelas tanaman yaitu Iris Setosa, Iris Versicolour, Iris Virginica berdasarkan lebar, tinggi sepal-nya dan lebar, tinggi petal-nya. Yang di dapatkan dari: https://archive.ics.uci.edu/ml/datasets/Iris

5. Dow Jones Index yang merupakan data yang akan digunakan untuk memprediksi harga saham yang dikumpulkan pada suatu periode waktu, dimana pada data tersebut setiap barisnya mencatat datanya setiap minggu, sehingga tujuan dari penggunaan klastering pada data ini adalah dapat menentukan saham mana yang akan menghasilkan tingkat terbesar kembali untuk menjadi pertimbangan berinvestasi di minggu berikutnya. Yang di dapatkan dari: https://archive.ics.uci.edu/ml/datasets/Dow+Jones+Index

\section{B. Artificial Bee Colony}

Artificial Bee Colony (ABC) merupakan salah satu algoritma optimasi yang memulai pencarian makanan. Seketika suatu tempat bernektar telah ditemukan, Employed bee akan menari (memberi tanda) agar nektar tersebut dapat dipanen oleh onlooker bee. Kemudian Onlooker bee akan menentukan mana saja sumber makanan yang baik untuk dipanen, dan meninggalkan sumber yang habis dan berubah menjadi scout bee. Scout bee bertugas mencari sumber baru yang dibuat secara acak pada ruang pencarian, dimana informasi posisi nektar yang lebih sedikit sebelumnya akan dilupakan oleh lebah tersebut sampai ditemukan posisi sumber makanan yang terbaik. [4].

Berikut langkah yang digunakan dalam $\mathrm{ABC}$ [4]:

1. Menentukan jumlah sumber makanan awal atau caloncalon solusi (SN) yang akan disebut $X i j$.

2. Mengevaluasi kecocokan $f_{i}$ (kualitas sumber makanan) pada populasi karena semakin banyak nektarnya semakin besar probabilitas sumber tersebut dipilih onlooker bee.

3. Masuk ke fase Employed Bee, yaitu menghitung Vij yang merupakan tetangga disekitar Xij.
4. Masuk ke fase Onlooker Bee yang akan mengerjakan langkah kedua dengan tujuan menggabungkannya menjadi sumber dengan probabilitas terbaik untuk setiap $k l a s t e r$-nya yang akan disebut $X i j$ baru. Sumber tersebut akan diulang langkah employed Bee, tetapi sumber terbaiknya akan disimpan di memori sebagai sumber terbaik pada iterasi ini.

5. Masuk ke fase Scout Bee, fase ini membangkitkan sumber baru dengan kondisi kumpulan sumber makanan belum mencapai batas limit Maximum Cycle Number. Fase ini akan menjembatani iterasi pertama ke iterasi kedua dan berikutnya.

6. Kumpulan sumber tersebut akan dibandingkan probabilitas kecocokannya hingga ditemukan sumber optimal.

$$
x_{i, j}=l_{j k}+\operatorname{rand}(0,1)\left(u_{j k}-l_{j k}\right)
$$

Dimana:

- $\mathrm{SN}=$ Jumlah sumber makanan

- $\mathrm{D}=$ Jumlah dimensi data

- $\mathrm{K}=$ Jumlah klaster

- $\mathrm{k}=\{1,2 \ldots, \mathrm{K}\}$

- $\mathrm{i}=\{1,2, \ldots, \mathrm{SN}\}$

- $\mathrm{j}=\{1,2, \ldots, \mathrm{D}\}$

- $x_{i, j}=$ Sumber makanan awal-i pada dimensi ke- $\mathrm{j}$

- $l_{j k}=$ nilai bawah dari tiap nilai yang ada di dimensi-j untuk tiap klaster

- $u_{j k}=$ nilai atas dari tiap dimensi-j untuk tiap klaster

- $\operatorname{rand}(0,1)=$ bangkitkan angka acak dengan distribusi normal 0 sampai 1 .

Menghitung fitness dengan cara:

$$
\begin{aligned}
& f_{i t_{i}}=\frac{1}{1+f_{i}} \\
& f_{i}=\frac{1}{D_{\text {Train }}} \sum_{j=1}^{D_{\text {Train }}} d\left(x_{j} p_{i}^{C L_{\text {known }}\left(x_{j}\right)}\right)
\end{aligned}
$$

Dimana:

- fit $_{i}=$ Fitness dari sumber makanan.

- $f_{i} \quad=$ Fungsi biaya dari permasalahan klaster .

- $\quad D_{\text {Train }}=$ Jumlah banyaknya data (sumber makanan) yang akan digunakan untuk menormalisasi penjumlahan yang akan digolongkan.

- $\quad p_{i}^{C L_{\text {known }}\left(x_{j}\right)}=$ Mendefinisikan kelas instansi data.

- $x_{j} \quad=$ Data ke-j.

Memulai siklus iterasi cycle sama dengan 1 hingga MCN.

Untuk setiap employed bee hitung solusi $v_{i}$ baru dengan cara:

$$
v_{i j}=z_{i j}+\phi_{i j}\left(z_{i j}-z_{k j}\right)
$$

Dimana:

- $v_{i j}=$ Kandidat posisi makanan baru berdasarkan posisi yang lama dalam memori. $k \in\{1,2, \ldots S N\}$ dan $j \in$ $\{1,2, \ldots D\}$ adalah indeks yang dipilih acak, namun $k$ harus berbeda indeks dengan $i$. 
- $\phi_{i j}=$ Angka acak diantara $\{-1,1\}$

Indeks acak pada persamaan tersebut bertujuan untuk mengontrol produksi sumber makanan tetangga di sekitar $z_{i, j}$ dan merepresentasikan perbandingan dua posisi sumber makanan yang terlihat pada lebah. Langkah berikutnya adalah hitung nilai $f_{i}$, dan lakukan proses pemilihan sumber makanan secara greedy di setiap klaster-nya.

Untuk setiap onlooker bee akan menentukan solusi $z_{-} i$ berdasarkan $p_{-} i$. Kemudian hitung nilai $v_{-} i$ sesuai langkah Employed Bee. Bandingkan kedua sumber makanan tersebut secara greedy. Berdasarkan hasil probabilitas, solusi terbaik pada iterasi ini akan disimpan.

Berdasarkan hasil probabilitas, solusi yang paling buruk ditinggalkan onlooker bee dan diganti dengan solusi baru yang secara acak didapatkan dari:

$$
z_{i}^{j}=z_{\text {min }}^{j}+\operatorname{rand}(0,1)\left(z_{\text {max }}^{j}-z_{\text {min }}^{j}\right)
$$

Dimana:

- $z_{i}=$ Sumber makanan yang di tinggalkan onlooker bee dan $j \in\{1,2, \ldots, D\}$.

Ulangi siklus hingga Maximum Cycle Number (MCN). Maximum Cycle Number atau limit untuk ABCKM dihitung dengan persamaan berikut:

$$
\text { limit }=S N * D
$$

Sumber makanan optimal didapatkan dari perbandingan nilai probabilitas kecocokan kumpulan sumber-sumber makanan tersebut.

\section{K-means}

$K$-means (KM) merupakan suatu algoritma klaster data yang mengelompokkan data berdasarkan data yang tidak berlabel kelas. Berikut langkah-langkah yang dilakukan dalam KM [3]:

1. Menentukan jumlah $\mathrm{k}$ (klaster).

2. Bangkitkan $k$ centroid (titik pusat klaster) awal secara acak.

3. Hitung jarak setiap data ke setiap centroid-nya menggunakan rumus korelasi antar dua objek yaitu Euclidean Distance pada setiap klaster.

4. Kelompokkan setiap data berdasarkan jarak terdekat antara data dengan centroid-nya.

5. Perbarui nilai centroid dengan nilai centroid

6. Ulangi langkah 3-5 hingga nilai centroid tidak berubah. Jarak antar input dengan centroid dihitung dengan cara:

$$
d\left(\overline{X_{i}}, \overline{Y_{j}}\right)=\sqrt{\left(x_{1}-y_{1}\right)^{2}+\cdots+\left(x_{n}-y_{n}\right)^{2}}
$$

\section{Dimana:}

- $\overline{X_{i}}=$ Vektor nilai input $\left\{x_{1}, x_{2}, \ldots, x_{n}\right\}$

- $\overline{Y_{j}}=$ Vektor nilai centroid $\left\{y_{1}, y_{2}, \ldots, y_{n}\right\}$

Memperbarui nilai centroid dengan nilai centroid baru dilakukan dengan cara:

$$
\mu_{k}=\frac{1}{N_{k}} \sum_{i=1}^{N_{k}} x_{i}
$$

Dimana:

- $\mu_{k}=$ Centroid baru dari klaster ke-k.

- $N_{k}=$ Banyaknya data pada klaster ke-k.

- $x_{i}=$ Vektor nilai input ke-i pada klaster ke-k.

Memilih titik pusat suatu klaster merupakan tugas yang rumit karena diatur maupun diacak, apabila nilai inisialisasi yang dilakukan kurang baik maka pengelompokan data bisa kurang optimal [3].

Pada ABCKM, hasil perhitungan jarak Euclidean akan menggantikan cost function $f_{i}$ pada $\mathrm{ABC}$, dan pemilihan centroid dilakukan menggunakan persamaan (1), dimana sumber makanan terdiri dari gabungan centroid-centroid pada setiap klaster-nya.

\section{Optimasi pada Artificial Bee Colony k-means}

Algoritma $K$-means akan digunakan pada setiap langkah Artificial Bee Colony untuk menyelesaikan permasalahan klastering untuk masing-masing sumber makanan pada setiap fase ABC.

Optimasi merupakan suatu proses untuk mendapatkan solusi yang paling optimal dari suatu permasalahan yang memiliki nilai tujuan maksimal atau minimal, tergantung mana yang diinginkan, tanpa melanggar batasan yang sebelumnya telah ditentukan. Penggunaan KM kerap menghasilkan solusi yang optimal. pada kandidat solusi di tetangga terdekatnya saja bukan keseluruhan dari semua solusi yang ada atau yang biasa disebut global optima. Sehingga dengan menggunakan ABC akan membantu agar tidak terjebak dalam lokal optima.

Pada algoritma ABCKM akan dihasilkan sumber-sumber makanan terbaik yang telah disimpan dari fase onlooker pada setiap iterasinya yang kemudian akan dipilih sumber optimalnya dengan cara yang sama yaitu berdasarkan probabilitas nilai fitness yang terbesar. Sehingga hasil terbaik tersebut akan di-KM untuk terakhir kalinya untuk mendapatkan hasil pembagian data/klasteringnya. sumber-sumber makanan tersebut.

Berikut akan dijelaskan metode ABCKM dengan menggunakan diagram alir yang akan mengilustrasikan langkah-langkah Artificial Bee Colony K-means secara umum yang akan dijelaskan pada Gambar 1 . Seperti yang diketahui ABCKM memiliki 4 fase utama selain masukan dan hasil keluarannya yaitu fase inisialisasi sumber makanan, employed bee, onlooker bee dan scout bee.

\section{E. Silhouette}

Algoritma Silhouette berperan besar dalam klastering, Silhouette merupakan algoritma yang mengenali kualitas pembagian data. Nilai koefisien silhouette berada pada rentang -1 hingga 1 dimana semakin mendekati -1 berarti hasil pembagian data tersebut buruk, dan sebaliknya. Nilai koefisien silhouette didapatkan dari:

$s i=\frac{b(i)-a(i)}{\max \{a(i), b(i)\}}$ 


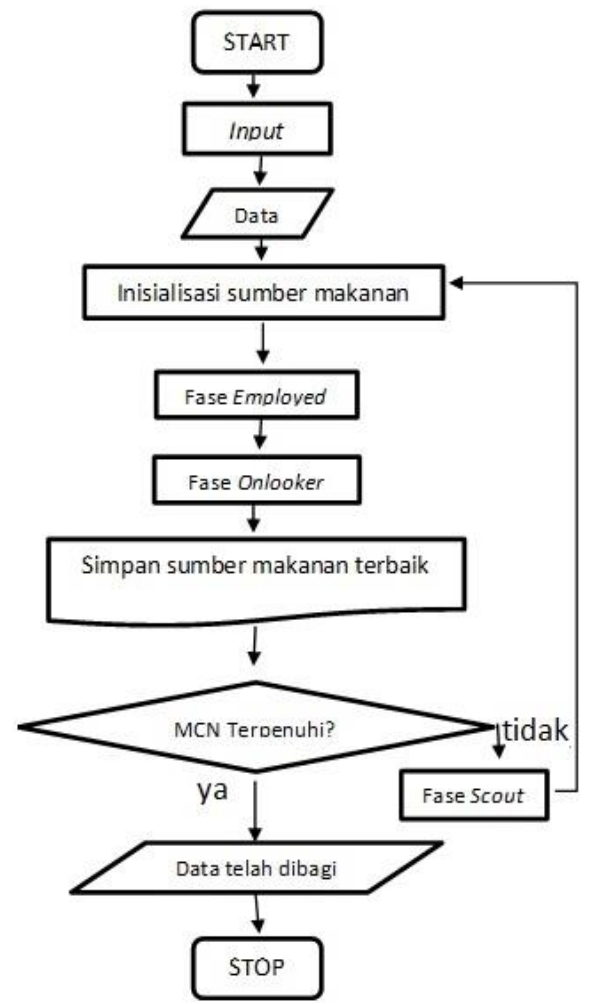

Gambar 1 Diagram Alir Artificial Bee Colony K-means

Dimana:

- $\quad i$ = Obyek data ke-i

- $\quad a$ = Rata-rata jarak i terhadap obyek lain pada klaster yang sama

- $\quad b=$ Nilai minimum dari rata-rata jarak i terhadap obyek lain pada klaster yang berbeda

- $\quad s i=$ Nilai koefisien silhouette

\section{HASIL DAN UJI COBA}

\section{A. Karakteristik Data}

Data masukan yang digunakan pada uji coba Tugas Akhir ini adalah beberapa dataset yang didapatkan dari berbagai sumber. Penjelasan mengenai macam-macam dataset yang digunakan telah dijelaskan pada Bab 1.

Data akan direpresentasikan kedalam suatu file dengan format text (txt). Pada Tabel 1 akan dijelaskan karakteristik kelima dataset sebagai berikut:

Tabel 1

Tabel Karakteristik Kelima Dataset

\begin{tabular}{|c|c|c|c|}
\hline Nama Dataset & Jumlah Fitur & Jumlah Data & Jenis Data \\
\hline $\begin{array}{l}\text { Wholesale } \\
\text { Costumer }\end{array}$ & 440 & 6 & Numerik \\
\hline Crime Rates & 16 & 7 & Numerik \\
\hline $\begin{array}{l}\text { Birth and Death } \\
\quad \text { Rates }\end{array}$ & 70 & 2 & Numerik \\
\hline Iris & 150 & 4 & Numerik \\
\hline Dow Jones Index & 750 & 16 & Numerik \\
\hline
\end{tabular}

B. Hasil Uji Coba Perbandingan Parameter

Perbandingan hasil uji coba ABCKM berupa nilai koefisien hasil pembagian data optimal yang akan dibandingkan dengan hasil pembagian data dengan KM yang digunakan. Berdasarkan berbagai dataset dengan parameter jumlah klaster, dimana hasil klaster dikatakan baik menurut algoritma silhouette adalah memiliki nilai koefisien diatas 0 dalam batas -1 hingga 1 .

Tabel 2

Uji Perbandingan Nilai Parameter Jumlah Klaster pada dataset crimerate.txt

\begin{tabular}{cccc}
\hline \hline \multirow{2}{*}{ No } & Parameter & \multicolumn{2}{c}{ Nilai koefisien silhouette } \\
& Jumlah klaster & ABCKM & KM \\
\hline 1 & 2 & 0.615 & 0.615 \\
2 & 3 & 0.460 & 0.460 \\
3 & 4 & 0.398 & 0.416 \\
4 & 6 & 0.445 & 0.414 \\
Rata-rata Nilai Koefisien & 0.479 & 0.476 \\
\hline \hline
\end{tabular}

Tabel 2 menunjukkan perbandingan hasil nilai koefisien silhouette pada dataset crimerate.txt dimana dapat diketahui bahwa nilai koefisien silhouette pada jumlah klaster dua untuk ABCKM dan KM memiliki nilai yang sama dan selain itu ABCKM memiliki nilai koefisien yang semakin menurun setiap kali ditambah jumlah klaster-nya berarti dua klaster adalah jumlah yang disarankan.

Nilai koefisien silhouette KM dan ABCKM kerap bernilai diatas 0 dan dibawah 0.5 yang berarti hasil klastering cukup baik, perbedaan selisih nilai koefisien silhouette yang dihasilkan ABCKM pada klaster 4 lebih buruk dibandingkan hasil dari KM sedangkan pada klaster 6 lebih baik melewati fase-fase pada ABCKM. Seilisih yang cukup besar tersebut memberikan rata-rata nilai silhouette yang lebih baik untuk $\mathrm{ABCKM}$, sehingga $\mathrm{ABCKM}$ berhasil mengklaster data dengan cukup baik pada dataset crimerate.

Tabel 3

Hasil Uji Perbandingan Nilai Parameter Jumlah Klaster pada dataset dowjonesindex.txt

\begin{tabular}{cccc}
\hline \hline \multicolumn{4}{c}{ dowjonesindex.txt } \\
\multirow{2}{*}{ No } & Parameter & \multicolumn{2}{c}{ Nilai koefisien silhouette } \\
& Jumlah klaster & $A B C K M$ & $K M$ \\
\hline 1 & 2 & 0.835 & 0.838 \\
2 & 3 & 0.827 & 0.843 \\
3 & 4 & 0.840 & 0.756 \\
4 & 5 & 0.772 & 0.723 \\
5 & 6 & 0.740 & 0.699 \\
\multicolumn{2}{c}{ Rata-rata Nilai Koefisien } & 0.802 & 0.771 \\
\hline \hline
\end{tabular}

Tabel 3 menunjukkan perbandingan hasil nilai koefisien silhouette pada dataset dowjonesindex.txt dimana parameter jumlah klaster-nya dapat diketahui bahwa nilai koefisien silhouette pada seluruh skenario ABCKM memiliki nilai koefisien tertinggi kecuali pada klaster tiga, dan data telah diklaster dengan baik.

Nilai koefisien silhouette KM yang dihasilkan mendekati hasil koefisien silhouette ABCKM, hal ini menandakan bahwa data memiliki kemiripan dan ketidakmiripan yang cukup kentara. Hasil KM lebih baik dari ABCKM terutama pada klaster kecil dua dan tiga, namun tidak pada jumlah klaster empat, lima dan enam yang menandakan ABCKM mampu membagi data lebih baik pada klaster yang lebih besar pada dataset dowjonesindex.

Tabel 4 menunjukkan perbandingan hasil nilai koefisien silhouette pada dataset wholesale.txt dimana parameter jumlah 
klaster-nya dapat diketahui bahwa nilai koefisien silhouette pada seluruh skenario jumlah klaster ABCKM lebih besar dari KM kecuali pada klaster 5.

Tabel 4

Hasil Uji Perbandingan Nilai Parameter Jumlah Klaster pada dataset wholesale.txt

\begin{tabular}{cccc}
\multicolumn{4}{c}{ wholesale.txt } \\
\hline \hline \multirow{2}{*}{ No } & Parameter & \multicolumn{2}{c}{ Nilai koefisien silhouette } \\
& Jumlah klaster & $A B C K M$ & KM \\
\hline 1 & 2 & 0.849 & 0.849 \\
2 & 3 & 0.708 & 0.649 \\
3 & 4 & 0.546 & 0.504 \\
4 & 5 & 0.561 & 0.566 \\
5 & 6 & 0.561 & 0.466 \\
\multicolumn{2}{c}{ Rata-rata Nilai Koefisien } & 0.645 & 0.606 \\
\hline \hline
\end{tabular}

Berdasarkan tabel 4 data telah di-klaster dengan baik, kecuali pada klaster empat, lima dan enam data di-klaster cukup baik, hal ini berarti bahwa pada kasus dataset wholesale sebaiknya menggunakan jumlah klaster kecil, karena pada klaster-klaster besar nampaknya data memiliki kesamaan diantara klaster-nya dan ketidaksamaan pada klaster lain yang sangat tipis.

Tabel 5 menunjukkan perbandingan hasil nilai koefisien silhouette pada dataset birthanddeathrates.txt dimana dapat diketahui bahwa nilai koefisien silhouette pada seluruh skenario jumlah klaster ABCKM memiliki nilai koefisien lebih tinggi kecuali pada klaster dua yang memiliki nilai koefisien silhouette sama dengan KM, dan data telah di-klaster dengan sangat baik karena data memiliki kemiripan disesama klasternya dan ketidakmiripan pada klaster lainnya.

Tabel 5

Hasil Uji Perbandingan Nilai Parameter Jumlah Klaster pada dataset birthandeathrates.txt

\begin{tabular}{|c|c|c|c|}
\hline \multirow{2}{*}{ No } & \multirow{2}{*}{$\begin{array}{c}\text { Parameter } \\
\text { Jumlah klaster }\end{array}$} & \multicolumn{2}{|c|}{ Nilai koefisien silhouette } \\
\hline & & $A B C K M$ & $K M$ \\
\hline 1 & 2 & 0.858 & 0.858 \\
\hline 2 & 3 & 0.749 & 0.683 \\
\hline 3 & 4 & 0.710 & 0.648 \\
\hline 4 & 5 & 0.703 & 0.703 \\
\hline 5 & 6 & 0.687 & 0.687 \\
\hline \multicolumn{2}{|c|}{ Rata-rata Nilai Koefisien } & 0.741 & 0.715 \\
\hline
\end{tabular}

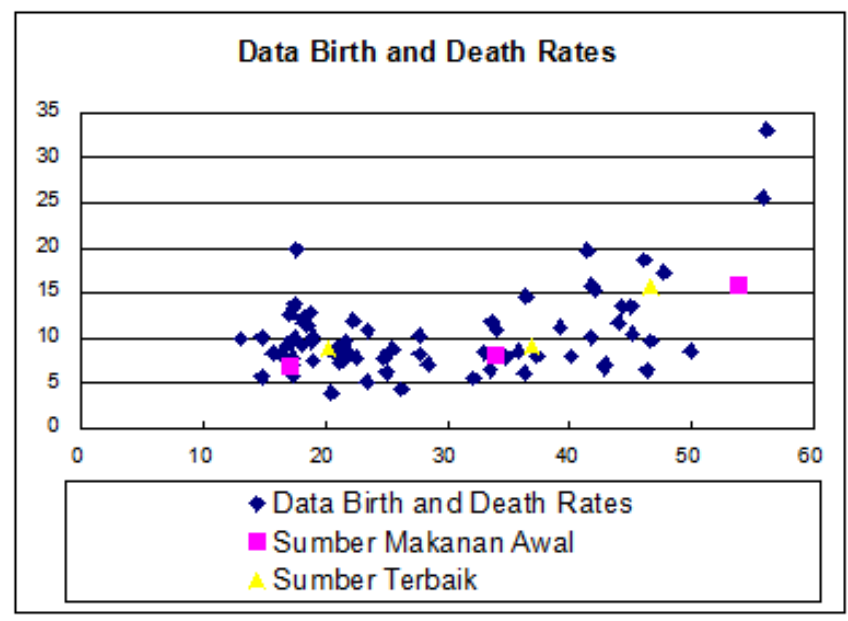

Gambar 2 Pembagian data Birth and Death Rates

Pada Gambar 2 sumbu x merupakan dimensi 1 yaitu birth rates/angka kelahiran, dan sumbu y merupakan dimensi 2 yaitu death rates/angka kematian. Data tersebut telah dibagi dengan klaster tiga berdasarkan perubahan letak sumber makanan awal dan sumber makanan optimal/terbaik.

Tabel 6

Hasil Uji Perbandingan Nilai Parameter Jumlah Klaster pada dataset iris.txt

\begin{tabular}{cccc}
\hline \hline \multirow{2}{*}{ No } & Parameter & \multicolumn{2}{c}{ Nilai koefisien silhouette } \\
& Jumlah klaster & $A B C K M$ & KM \\
\hline 1 & 2 & 0.847 & 0.850 \\
2 & 3 & 0.735 & 0.735 \\
3 & 4 & 0.667 & 0.666 \\
4 & 5 & 0.502 & 0.669 \\
5 & 6 & 0.555 & 0.556 \\
\multicolumn{2}{c}{ Rata-rata Nilai Koefisien } & 0.661 & 0.684 \\
\hline \hline
\end{tabular}

Tabel 6 menunjukkan perbandingan hasil nilai koefisien silhouette ketiga algoritma pada dataset iris.txt dimana dapat diketahui bahwa nilai koefisien silhouette pada seluruh klaster ABCKM memiliki hasil yang lebih sedikit dibandingkan kecuali pada klaster empat dan tiga yang memiliki nilai sama, data telah di-klaster dengan baik, kecuali pada klaster besar lima dan enam, karena memang perhitungan klasifikasi dan klastering berbeda.

Tabel 7

Hasil Pengujian Confusion Matrices Data Iris

\begin{tabular}{cccccc}
\hline \hline \multirow{2}{*}{ No. } & \multirow{2}{*}{ Variabel } & \multicolumn{5}{c}{ Jumlah Klaster } & \multirow{2}{*}{ Total } \\
\hline 1 & True Positives $(T P)$ & 50 & 46 & 35 & 131 \\
2 & False Positives $(F P)$ & 4 & 15 & 0 & 19 \\
3 & False Negatives $(F N)$ & 0 & 4 & 15 & 19 \\
4 & True Negatives $(T N)$ & 96 & 85 & 100 & 281 \\
\hline \hline
\end{tabular}

Hasil klastering data iris pada klaster tiga akan dibandingkan dengan klasifikasi data aktual pada setiap klaster-nya yang diilustrasikan pada Tabel 7. Berdasarkan hasil confusion matrix tersebut, diperoleh nilai akurasi, error rate, presisi, dan recall sebagai berikut:

$$
\text { Akurasi }=\frac{131+19}{131+19+19+281} * 100 \%=91.6 \%
$$

$$
\begin{gathered}
\text { Error rate }=\frac{19+19}{131+19+19+281} * 100 \%=8.4 \% \\
\text { Presisi }=\frac{131}{131+19}=0.87 \\
\text { Recall }=\frac{131}{131+19}=0.87
\end{gathered}
$$

Akurasi dari hasil klastering $\mathrm{ABCKM}$ sangat tinggi yaitu 91.6\% yang berarti klastering ABCKM menyerupai klasifikasi data aktual iris dengan tingkat kesalahan kurang dari $10 \%$ yaitu $8.4 \%$.

Tabel 8 menunjukkan rata-rata total keempat dataset khusus 
permasalahan klastering, berdasarkan tabel tersebut diketahui bahwa rata-rata nilai koefisien silhouette ABCKM untuk keempat dataset lebih baik rata-rata nilai koefisien silhouette dari KM.

Tabel 8

Rata-rata Total Hasil Uji Perbandingan Nilai Parameter Jumlah Klaster pada keempat dataset selain iris

\begin{tabular}{clrc}
\hline \hline No. & Rata-rata nilai koefisien dataset & ABCKM & KM \\
\hline 1 & Crime Rate & 0.479 & 0.476 \\
2 & Dow Jones Index & 0.802 & 0.771 \\
3 & Wholesale Costumer & 0.645 & 0.606 \\
4 & Birth and Death Rates & 0.741 & 0.715 \\
& Rata-rata total & 0.667 & 0.642 \\
\hline \hline
\end{tabular}

\section{KESIMPULAN}

Kesimpulan yang diperoleh berdasarkan pengujian dan evaluasi yang telah dilakukan adalah sebagai berikut:

1. Metode ABCKM telah terbukti dapat menyelesaikan permasalahan pembagian data.

2. Berdasarkan hasil koefisien silhouette untuk keempat dataset pada uji coba memberikan rata-rata nilai koefisien 0.67 yang berarti ABCKM mampu mengklaster data dengan baik, sedangkan KM biasa 0.64 .

3. Berdasarkan perhitungan silhouette untuk dataset iris pada jumlah klaster tiga didapati bahwa ABCKM menghasilkan nilai koefisien silhouette 0.73 dan akurasi klasifikasi data yang sangat tinggi yaitu $91.6 \%$.

4. Kinerja algoritma ABCKM sering ditemukan lebih baik dari KM.

Saran yang hendak disampaikan terkait dengan Tugas Akhir ini adalah diperlukannya peninjauan ulang kembali dalam menentukan nilai parameter lain yang akan digunakan, juga dibutuhkan metode pengujian lain untuk permasalahan klastering.

\section{UCAPAN TERIMA KASIH}

Penulis A.B.N. mengucapkan puji syukur kepada Allah SWT. Yang melimpahkan rahmat dan hidayah-Nya sehingga penulis dapat menyelesaikan penelitian dengan lancar. Penulis juga mengucapkan terima kasih kepada Ibu Diana Purwitasari dan Ibu Chastine Fatichah yang telah banyak membantu penulis dalam menyelesaikan penelitian ini. Penulis juga menyampaikan ucapan terima kasih kepada pihak-pihak lain yang turut membantu terselesaikannya penelitian ini.

\section{DAFTAR PUSTAKA}

[1] Pham, D. T., Otri, S., Afifiy, A., Mahmuddin, M., \& Al-Jabbouli, H. (2007). Data Clustering Using the Bees Algorithm.

[2] Kacprzyk, J., \& Pedrycz, W. (2015). Springer Handbook of Computational Intelligence.

[3] Aggarwal, C. C. (2015). Data Mining: The Textbook. New York.

[4] Karaboga, D., \& Ozturk, C. (2009). A Novel Clustering Approach: Artificial Bee Colony (ABC) algorithm. 